\title{
Parenteral Nutrition-Induced Cholestasis in Neonates: Where Does the Problem Lie?
}

\author{
Kheira Jolin-Dahel, ${ }^{1}$ Emanuela Ferretti, ${ }^{1,2}$ Carolina Montiveros, ${ }^{1,2}$ Renee Grenon, ${ }^{3}$ \\ Nick Barrowman, ${ }^{3}$ and Carolina Jimenez-Rivera ${ }^{1,2}$ \\ ${ }^{1}$ University of Ottawa, Ottawa, ON, Canada K1H $8 \mathrm{Ll}$ \\ ${ }^{2}$ Department of Pediatrics, Children's Hospital of Eastern Ontario, 401 Smyth Road, Ottawa, ON, Canada K1H 8L1 \\ ${ }^{3}$ Department of Statistics, Children's Hospital of Eastern Ontario, 401 Smyth Road, Ottawa, ON, Canada K1H 8L1
}

Correspondence should be addressed to Carolina Jimenez-Rivera; cajimenez@cheo.on.ca

Received 2 August 2013; Accepted 5 October 2013

Academic Editor: Massimo Raimondo

Copyright (C) 2013 Kheira Jolin-Dahel et al. This is an open access article distributed under the Creative Commons Attribution License, which permits unrestricted use, distribution, and reproduction in any medium, provided the original work is properly cited.

\begin{abstract}
Background. Parenteral nutrition (PN) is an effective method of nourishing the neonate who is unable to receive full enteral feeds. Cholestasis can be a complication of PN and can lead to severe liver damage. Aim. We describe our patient population and determine risk factors for developing PN cholestasis. Methods. Retrospective chart review of newborns admitted from January 2006 to May 2011 to the Neonatal Intensive Care Unit at our institution and received PN $>14$ days. Cholestasis was defined as serum conjugated bilirubin $>50 \mu \mathrm{mol} / \mathrm{L}$. Results. Eighty-seven newborns were included; 18 (20.7\%) developed PN cholestasis. The most frequent surgical condition for both groups was gastroschisis $(8 / 87 ; 9.2 \%)$. No significant differences were found between the cholestasis and control groups for the following parameters: birth weight, gestational age, intrauterine growth restriction, Apgar scores, and day of life at initiation of enteral feeds. Duration of PN in days and dosage of carbohydrates in $\mathrm{g} / \mathrm{kg} / \mathrm{day}$ were significantly higher in the cholestasis group than the control group. Conclusion. PN-related cholestasis presented in one-fifth of neonates receiving $\mathrm{PN}$ for more than two weeks. Longer duration of PN and higher dosage of carbohydrates were independent risk factors for the development of PN cholestasis in this population.
\end{abstract}

\section{Introduction}

The use of parenteral nutrition (PN) alone or in combination with enteral nutrition in neonates is effective in providing sufficient nutrients to maintain growth in the ill newborn infant. Cholestasis is a frequent complication of PN $[1,2]$. The etiology of PN liver disease is unknown and likely multifactorial [3]. There have been multiple risk factors associated with PN-related cholestasis such as low birth weight [4], prematurity, duration of PN, sepsis, absence of enteral feeding, quality or quantity of amino acid intake $[5,6]$, male gender [7], mineral trace toxicity, toxicity from plant phytosterols [8], and perinatal depression or shock [6]. Intestinal resection and its complications have been also associated with the occurrence of PN-related cholestasis [2]. In some cases, progressive liver damage, liver failure, and death can occur [9].

Our aim was to describe the prevalence and risk factors for developing PN-related cholestasis in the neonatal period at the level III Neonatal Intensive Care Unit (NICU) at the Children's Hospital of Eastern Ontario.

\section{Methods}

We conducted a retrospective chart review of neonates admitted to the NICU at the Children's Hospital of Eastern Ontario who received PN for more than 14 days from January 1, 2006, to May 31, 2011. PN-related cholestasis was defined as an elevation of conjugated bilirubin greater than or equal to $50 \mu \mathrm{mol} / \mathrm{L}$ subsequent to initiation of $\mathrm{PN}$.

Clinical information included gestational age, birth weight, gender, Apgar score at 5 minutes less than 6, number of episodes of necrotizing enterocolitis and sepsis, gastrointestinal tract anomalies, bowel resection, day of life at initiation of $\mathrm{PN}$, duration of $\mathrm{PN}$, parenteral dosage in $\mathrm{g} / \mathrm{kg} / \mathrm{d}$ of protein, carbohydrates and lipids, vitamin and mineral trace element intake, and day of life (DOL) when enteral feeds were started. 
TABLE 1: Demographics of patients (exposed to PN for at least 2 weeks).

\begin{tabular}{|c|c|c|c|}
\hline & $\begin{array}{c}\text { Control } \\
(N=69)\end{array}$ & $\begin{array}{l}\text { Cholestasis } \\
(N=18)\end{array}$ & $P$ value \\
\hline Gender, male (\%) & $37(53.6)$ & $15(83.3)$ & $0.023^{\mathrm{ax}}$ \\
\hline Birth weight, grams, mean (SD) & $1,781( \pm 1013)$ & $1980( \pm 997)$ & $0.340^{\text {a }}$ \\
\hline \multicolumn{4}{|l|}{ Gestational age, $N(\%)$} \\
\hline$<32+0 / 7$ WGA & $31(44.9)$ & $8(44.4)$ & $0.759^{\mathrm{s}}$ \\
\hline $32+0 / 7-36+6 / 7 \mathrm{WGA}$ & $18(26)$ & $4(22.2)$ & \\
\hline $37+0 / 7-38 \mathrm{WGA}$ & $4(5.8)$ & $1(5.6)$ & \\
\hline$>38 \mathrm{WGA}$ & $16(23.2)$ & $5(27.8)$ & \\
\hline Apgar $<6$ at $5 \mathrm{~min}, N(\%)$ & $14(20.3)$ & $4(23.5)$ & $0.515^{\dagger}$ \\
\hline IUGR, $N(\%)$ & $10(14.5)$ & $2(11.1)$ & $1.00^{\mathrm{s}}$ \\
\hline Number of episodes of sepsis, mean (SD) & $0.78( \pm 0.9)$ & $0.72( \pm 1.0)$ & $0.645^{\text {a }}$ \\
\hline \multicolumn{4}{|l|}{ Top 2 GI abnormality } \\
\hline No. 1 & Gastroschisis (6) & Gastroschisis (2) & NA \\
\hline No. 2 & Bowel perforation (5) & NA & NA \\
\hline
\end{tabular}

PN: parenteral nutrition, IUGR: intrauterine growth restriction, NEC: necrotizing enterocolitis, GI: gastrointestinal, WGA: weeks of gestational age, ${ }^{\mathrm{s}}$ Fisher's exact test, ${ }^{\not}$ Mann-Whitney $U,{ }^{\dagger}$ Pearson chi-squared test.

Baseline laboratory investigation included alanine aminotransferase (ALT), aspartate aminotransferase (AST), alkaline phosphatase, gamma glutamyl transpeptidase (GGT), and bilirubin (conjugated and total) levels. Hepatic synthetic function included albumin and coagulation tests (international normalized ratio and partial thrombin time). Routine blood tests as per PN protocol were performed twice a week.

Patients who were found to have a conjugated bilirubin level above $50 \mu \mathrm{mol} / \mathrm{L}$ were classified as the cholestasis group. Follow-up blood work was recorded at discharge, transfer, or resolution of $\mathrm{PN}$-related cholestasis. Infectious causes of cholestasis including viral serology (Hep B sAg, Hep B sAb, Hep A IgM and IgG, Hep C serology, EBV, and toxoplasmosis) were included in our data files. Metabolic and endocrine disorders (such as $\alpha-1$ antitrypsin deficiency, and galactosemia, hypothyroidism) were ruled out as well as anatomical obstructive causes (e.g., biliary atresia) and Alagille syndrome.

Characteristics of PN solution (concentration of lipids, amino acids, vitamin, and mineral trace element) were recorded.

Between-group comparisons of categorical variables were performed using Fisher's exact test and Pearson's chi-squared test as appropriate. Between-group comparisons of continuous variables were performed using Mann-Whitney $U$ test. Two-sided $P$ values $<0.05$ were considered statistically significant. Unadjusted and adjusted associations between potential risk factors, like duration of TPN and dosage of carbohydrates, lipids, and amino acids, and cholestasis were examined using logistic regression. Odds ratios were obtained, together with $95 \%$ confidence intervals. To summarize the fitted risk, predicted probabilities of cholestasis were obtained at the midpoints of intervals of the risk factors that were found to be statistically significant in the multiple logistic regression model.

\section{Results}

There were 2,487 neonates admitted to the NICU during the study period. Eighty-seven newborns met the study criteria of receiving PN more than 14 days and were included in this study. The mean age of initiation of PN was $5 \pm 9 \mathrm{~d}$ of life. Demographic distribution of patients between both groups was compared and no difference was found between the control and cholestasis groups, except for higher number of males in the control group. We also compared medical conditions distribution and incidence of sepsis and episodes of necrotizing enterocolitis (NEC) between both groups and found no statistical difference. The most common gastrointestinal abnormality present in both groups was gastroschisis (8/87; 9.2\%). Patient characteristics are reported in Table 1.

Eighteen $(20.7 \%)$ out of 87 neonates had values of conjugated bilirubin $\geq 50 \mu \mathrm{mol} / \mathrm{L}$ and were considered to have cholestasis; the remaining 69 served as the control group. Median DOL of bilirubin $>50 \mu \mathrm{mol} / \mathrm{L}$ was $32.4 \pm 22 \mathrm{~d}$; peak bilirubin level was $90 \mu \mathrm{mol} / \mathrm{L}$ (IQR 68, $130 \mu \mathrm{mol} / \mathrm{L}$ ). Children with cholestasis also had elevation of liver enzymes with a mean ALT of $140 \pm 195 \mathrm{U} / \mathrm{L}$ and AST of $215 \pm 367 \mathrm{U} / \mathrm{L}$. Other causes of cholestatic liver disease including infectious, metabolic, endocrine, obstructive, and syndromic causes were ruled out.

3.1. Parenteral Nutrition (PN). The duration of PN and dosage of each nutrient were compared between both groups. Neonates in the cholestasis group received $\mathrm{PN}$ for a longer period than the control group ( $39 \mathrm{~d}$ versus $20 \mathrm{~d} ; P=0.001$ ). The dosage of carbohydrates in $\mathrm{g} / \mathrm{kg} /$ day was significantly higher in the cholestasis group than in the control group (14.4 versus $12.5 ; P=0.002)$. We found no significant differences in the dosage of amino acids and lipids for both groups. Dosage and duration of PN are reported in Table 2; unadjusted and 
TABLE 2: Composition and duration of PN.

\begin{tabular}{|c|c|c|c|}
\hline & Control $(N=69)$ & Cholestasis $(N=18)$ & $P$ value \\
\hline Duration of PN, days, median (IQR) & $20(15-31)$ & $39(24.2-53.0)$ & $0.001^{\mathrm{a} *}$ \\
\hline Introduction of enteral feeds DOL, median (IQR) & $8.0(3.3-19.8)$ & $14.0(5.5-36.5)$ & $0.29^{\mathrm{g}}$ \\
\hline $\mathrm{CH}$ g/kg/day, median (IQR) & $12.5(10.0-13.2)$ & $14.4(12.5-16.2)$ & $0.002^{\mathrm{a} *}$ \\
\hline Lipids g/kg/day, median (IQR) & $3.0(3.0-3.0)$ & $3.0(3.0-3.4)$ & $0.49^{\alpha}$ \\
\hline AA g/kg/day, median (IQR) & $3.5(3.0-3.5)$ & $3.5(3.5-4.0)$ & $0.01^{\mathrm{d}}$ \\
\hline
\end{tabular}

PN: parenteral nutrition, $\mathrm{CH}$ : carbohydrate, aa: amino acid, DOL: days of life. ${ }^{\text {o }}$ Statistical analysis with the Mann-Whitney test. ${ }^{*} P$ value is statistically significant.

TABLE 3: Patient characteristics within cholestasis group.

\begin{tabular}{lcc}
\hline & Omegaven $(N=6)$ & No Omegaven $(N=12)$ \\
\hline Gender, males (\%) & $6(100)$ & $9(75)$ \\
Birth weight (g), Mean (SD) & $1,598 \pm 614$ & $71 \pm 1117$ \\
Preterm, $N$ (\%) & $6(100)$ & $2(58.3)$ \\
IUGR, $N$ (\%) & $6(100)$ & $4(36.4)$ \\
Apgar $<$, $N$ (\%) & $6(100)$ & $37.8 \pm 24.67$ \\
DOL conj bili above $50 \mu$ mol/L, mean (SD) & $21.7 \pm 12.69$ & $67.4 \pm 13.8$ \\
1st conj bili above $50 \mu$ mol/L, mean (SD) & $64.7 \pm 15.4$ & $38(24.2-52.3)$ \\
Duration of PN, median (IQR) & $52(21,69.8)$ & $9.0(2.5-17.5)$ \\
DOL enteral feed started, median (IQR) (SD) & $37.0(27.8-65.8)$ & $14.0(12.5-15.6)$ \\
PN CH/kg/day, max, median (IQR) & $15.0(13.1-16.5)$ & $3.1(3.0-3.5)$ \\
PN lip/kg/day, max, median(IQR) & $3.0(2.3-3.0)$ & $3.5(3.5-3.8)$ \\
PN aa/kg/day, max, median (IQR) & $4.0(3.6-4.0)$ & NA \\
Day start OV while on PN mean (SD) & $18 \pm 12.2$ & NA \\
Duration OV, median (IQR) & $21.0(13.5-97.0)$ & NA \\
Conj bili when OV started, $(\mu \mathrm{mol} / \mathrm{L})$, mean $(\mathrm{SD})$ & $48.3 \pm 16.60$ & \\
\hline
\end{tabular}

PN: parenteral nutrition, IUGR: intrauterine growth restriction, conj bili: conjugated bilirubin, CH: carbohydrates, lip: lipids, aa: amino acids, OV: Omegaven, DOL: days of life.

TABle 4: Probability of cholestasis predicted by logistic regression model including duration of TPN and dose of carbohydrate.

\begin{tabular}{lrrrrrrr}
\hline $\begin{array}{l}\text { Dose of CH } \\
\text { (g/kg/day) }\end{array}$ & $2-4$ & $4-6$ & $6-8$ & $8-10$ & $10-12$ & $12-14$ & $14-16$ \\
\hline $5-10$ & $2 \%$ & $3 \%$ & $6 \%$ & $12 \%$ & $20 \%$ & $33 \%$ & $48 \%$ \\
$10-15$ & $10 \%$ & $17 \%$ & $29 \%$ & $43 \%$ & $60 \%$ & $74 \%$ & $85 \%$ \\
$15-20$ & $39 \%$ & $55 \%$ & $70 \%$ & $82 \%$ & $90 \%$ & $94 \%$ & $97 \%$ \\
\hline
\end{tabular}

adjusted odds ratios for cholestasis are reported in Figure 1. In the multiple logistic regression model, only duration of TPN (adjusted OR 1.36 per week, 95\% CI 1.06-1.75) and dosage of carbohydrates (adjusted OR 1.38, 95\% CI 1.05-1.81) were statistically significant.

Six neonates $(6 / 18 ; 33.3 \%)$ in the cholestasis group and 1 $(1 / 69 ; 1.4 \%)$ in the control group received Omegaven starting at mean day 21 into the course of receiving parenteral nutrition (range $=8-39 \mathrm{~d}$ ). Characteristics of patients receiving Omegaven are shown in Table 3.

Table 4 describes the probability of developing cholestasis using a logistic regression model including duration of PN and dosage of carbohydrates.

\section{Discussion}

Cholestasis is a commonly described complication of PN. Its etiology is not fully understood and is thought to be multifactorial [9]. Proposed mechanisms included altered bile salt metabolisms secondary to prematurity and toxic effect of PN components on the liver and gastrointestinal systems [10]. Aggravating factors such as sepsis and duration of bowel rest have also been described $[11,12]$.

4.1. Prematurity, Low Birth Weight, and Duration of PN. Our study did not reveal differences among premature and full-term newborns in the cholestatic and control groups. Prematurity, low birth weights, and duration of $\mathrm{PN}$ are often described as risk factors for developing $\mathrm{PN}$-induced cholestasis $[13,14]$. These risk factors are hard to separate because premature and low birth weight newborns will likely require $\mathrm{PN}$ for longer periods of time [15].

In our study, we did not find a higher proportion of intrauterine growth restriction (IUGR) in the cholestasis group. Baserga and Kelly $[4,15]$ compared the incidence of $\mathrm{PN}$-induced cholestasis in extremely low birth weight infants who were either premature or had suffered from IUGR. They found that the IUGR group had a higher incidence of PN-induced cholestasis (56\% versus 27\%). Similiar studies 


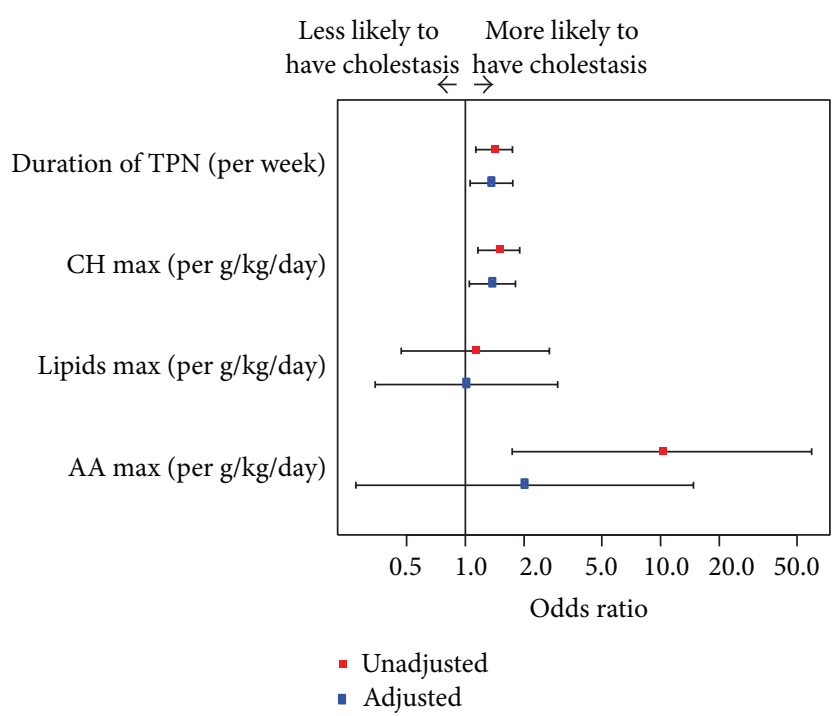

FIGURE 1: Unadjusted and adjusted odds ratios from logistic regression.

have shown these findings and attributed them to metabolic and physiological changes to the hepatocytes secondary to uteroplacental insufficiency [15-17], specifically alteration in expression of glucose transporters [18] and higher susceptibility to infections [19]. Both of their groups had similar composition in PN nutrients. However, their IUGR group had a significantly longer duration of enteral rest which has also been identified as a risk factor for developing PNinduced cholestasis.

We identified, however, that the cholestasis group received $\mathrm{PN}$ for a longer period of time (39 versus $20 \mathrm{~d}$; $P=$ 0.003 ) compared to the control group. Our data suggests that the duration of $\mathrm{PN}$ itself is a risk factor for cholestasis similar to what is described in the literature [20].

4.2. Duration of Enteral Rest. When comparing the DOL at which enteral feeds were introduced and sustained, we did not observe any significant difference between the control and the cholestasis groups. Moreover, many patients (11 in the cholestasis and 51 in the control groups) were receiving at least some enteral stimulation concomitant to the administration of PN. These results support the hypothesis that the PN mixture causes toxicity, independently of whether there is enteral stimulation or not. However, with these results, we cannot exclude the possibility of length of enteral rest as an aggravating factor.

Lack of enteral stimulation has been suggested to be a risk factor for developing $\mathrm{PN}$-induced cholestasis by various mechanisms [19, 21-24]. First, it is thought that lack of enteral stimulation reduces growth factors secretions that would normally promote enterocyte maturations; second, there is also a decrease in secretion of gut hormones such as cholecystokinin, hence promoting bile stasis and decreasing enterohepatic circulation [15]. Moreover, intestinal stasis leads to bacterial overgrowth. Studies have shown that endotoxins from gram-negative bacteria can inhibit bile secretions leading to cholestasis and that premature infants are more susceptible to these toxins $[15,25,26]$.

\subsection{Composition of PN Solution}

4.3.1. Amino Acids. There are numerous reports favoring the different components of $\mathrm{PN}$ as the main cause of its toxicity. Vileisis et al. [27] reported that patients receiving a higher dosage of amino acids in PN (high: $3.6 \mathrm{~g} / \mathrm{kg} /$ day compared to low: $2.3 \mathrm{~g} / \mathrm{kg} /$ day) developed cholestasis in a shorter period of time and the peak bilirubin level was higher. Our data analysis demonstrated no difference in the concentration of amino acids when comparing both groups. Within our cholestasis group, all patients had a similar amino acid dosage, as seen by the small standard deviation, despite the wide range in onset of cholestasis. It did not appear that amino acid dosage was a risk factor in our patient population in the multivariate analysis.

4.3.2. Carbohydrates. We did, however, find that our cholestasis group received a higher dosage of carbohydrates in their PN composition (14.4 versus $12 \mathrm{~g} / \mathrm{kg} / \mathrm{d} ; P=0.02$ ), in agreement with previously published results identifying high carbohydrate content as a risk factor for developing PN cholestasis $[27,28]$.

Animal models have shown that high dextrose levels in PN solutions correlate with altered levels of insulin and glucagon in plasma as well as alteration in hepatocyte morphology, associated with increased periportal fatty infiltration [29]. In addition, it has been recommended that dextrose levels in the PN-solution should be administered at levels not greater than $7 \mathrm{~g} / \mathrm{kg} /$ day [19].

4.3.3. Lipids. In our study, we did not find any difference in the lipid dosage when comparing both groups, agreeing that lipid concentration is not a sole risk factor for developing cholestasis. It has been previously suggested that caloric excess caused by lipid overload could lead to steatosis and cholestasis $[15,27,30,31]$. Specifically, it has been recommended that lipid concentration should not exceed $2.5 \mathrm{~g} / \mathrm{kg} /$ day [32] and that dosage higher than $1 \mathrm{~g} / \mathrm{kg} / \mathrm{day}$ correlated with liver damage $[33,34]$. Although excess lipid has been shown to accumulate in Kupffer cells $[35,36]$, there is no evidence that it directly causes cholestasis and if so, the mechanism is still not well understood [13, 27, 37-39].

4.3.4. Omegaven. In our study, only six of 18 patients who developed PN-induced cholestasis received Omegaven. Unfortunately, this small number was not enough to generate meaningful statistical analysis. So far, studies demonstrated that patients who received Omegaven after developing PNinduced cholestasis have a higher rate of reversal when compared to patients who received soy-based emulsion [40]. Animal studies have proven that parenteral fish oil did not impair bile secretion and prevented steatosis [41, 42]. Soybased fat emulsions contain phytosterols that have been recently identified as primary offending agents in PN-related cholestasis $[15,32,43]$. Fish oil, on the other hand, does 
not contain any phytosterols and contains omega-3 polyunsaturated fatty acids which have known anti-inflammatory properties [44-46].

In summary, PN-related cholestasis was not highly prevalent in our patient population, with only $20.7 \%$ compared to $24 \%$ and $35 \%$ reported by other authors [47, 48]. One of the limitations of this study is the small number of patients in the cholestasis group as well as patients receiving Omegaven, which did not allow for comparisons amongst the groups. However, we conclude that the onset of PN-induced cholestasis is likely multifactorial. We identified two risk factors by our data analysis: duration of $\mathrm{PN}$ and high levels of carbohydrates. We believe that our predicted probability of developing PN cholestasis (see Table 4) could serve as a guideline to adjust or modify these two factors to prevent the occurrence of this condition in the newborn.

\section{Conflict of Interests}

The authors have no conflict of interests to declare nor any financial interests with pharmaceutical companies related to this study.

\section{Acknowledgment}

The authors would like to thank the Pediatric Liver Foundation for their financial support for the study.

\section{References}

[1] F. J. Suchy, "Neonatal cholestasis," Pediatrics in Review, vol. 25, no. 11, pp. 388-396, 2004.

[2] J. M. Sondheimer, E. Asturias, and M. Cadnapaphornchai, "Infection and cholestasis in neonates with intestinal resection and long-term parenteral nutrition," Journal of Pediatric Gastroenterology and Nutrition, vol. 27, no. 2, pp. 131-137, 1998.

[3] N. F. Sheard and R. E. Kleinman, "TPN cholestasis in premature infants: the role of parenteral nutrition solutions," Pediatric Annals, vol. 16, no. 3, pp. 243-248, 1987.

[4] M. C. Baserga and A. Sola, "Intrauterine growth restriction impacts tolerance to total parenteral nutrition in extremely low birth weight infants," Journal of Perinatology, vol. 24, no. 8, pp. 476-481, 2004.

[5] M. Steinbach, R. H. Clark, A. S. Kelleher et al., "Demographic and nutritional factors associated with prolonged cholestatic jaundice in the premature infant," Journal of Perinatology, vol. 28, no. 2, pp. 129-135, 2008.

[6] K. Wright, K. D. Ernst, M. S. Gaylord, J. P. Dawson, and T. M. Burnette, "Increased incidence of parental nutrition-associated cholestasis with aminosyn PF compared to Trophamine," Journal of Perinatology, vol. 23, no. 6, pp. 444-450, 2003.

[7] M. J. Albers, D.-A. H. De Gast-Bakker, N. A. M. Van Dam, G. C. Madern, and D. Tibboel, "Male sex predisposes the newborn surgical patient to parenteral nutrition-associated cholestasis and to sepsis," Archives of Surgery, vol. 137, no. 7, pp. 789-793, 2002.

[8] P. T. Clayton, P. Whitfield, and K. Iyer, "The role of phytosterols in the pathogenesis of liver complications of pediatric parenteral nutrition," Nutrition, vol. 14, no. 1, pp. 158-164, 1998.
[9] A. L. Buchman, K. Iyer, and J. Fryer, "Parenteral nutrition-associated liver disease and the role for isolated intestine and intestine/liver transplantation," Hepatology, vol. 43, no. 1, pp. 9-19, 2006.

[10] D. R. Duerksen, J. E. Van Aerde, G. Chan, A. B. R. Thomson, L. J. Jewell, and M. T. Clandinin, "Total parenteral nutrition impairs bile flow and alters bile composition in newborn piglet," Digestive Diseases and Sciences, vol. 41, no. 9, pp. 1864-1870, 1996.

[11] R. H. Moseley, "Sepsis-associated cholestasis," Gastroenterology, vol. 112, no. 1, pp. 302-306, 1997.

[12] J. C. Alverdy, E. Aoys, and G. S. Moss, “Total parenteral nutrition promotes bacterial translocation from the gut," Surgery, vol. 104, no. 2, pp. 185-190, 1988.

[13] E. F. Beale, R. M. Nelson, and R. L. Bucciarelli, "Intrahepatic cholestasis associated with parenteral nutrition in premature infants," Pediatrics, vol. 64, no. 3, pp. 342-347, 1979.

[14] R. J. Merritt, "Cholestasis associated with total parenteral nutrition," Journal of Pediatric Gastroenterology and Nutrition, vol. 5, no. 1, pp. 9-22, 1986.

[15] D. A. Kelly, "Liver complications of pediatric parenteral nutrition-epidemiology," Nutrition, vol. 14, no. 1, pp. 153-157, 1998.

[16] G. Boehm, D. M. Muller, B. Teichmann, and P. Krumbiegel, "Influence of intrauterine growth retardation on parameters of liver function in low birth weight infants," European Journal of Pediatrics, vol. 149, no. 6, pp. 396-398, 1990.

[17] G. Boehm, H. Senger, W. Braun, K. Beyreiss, and N. C. R. Raiha, "Metabolic differences between AGA- and SGA-infants of very low birthweight-I. Relationship to intrauterine growth retardation," Acta Paediatrica Scandinavica, vol. 77, no. 1, pp. 1923, 1988.

[18] R. H. Lane, S. E. Crawford, A. S. Flozak, and R. A. Simmons, "Localization and quantification of glucose transporters in liver of growth-retarded fetal and neonatal rats," American Journal of Physiology: Endocrinology and Metabolism, vol. 276, no. 1, pp. E135-E142, 1999.

[19] F. W. Guglielmi, N. Regano, S. Mazzuoli et al., "Cholestasis induced by total parenteral nutrition," Clinics in Liver Disease, vol. 12, no. 1, pp. 97-110, 2008.

[20] S. Suita, K. Ikeda, A. Nagasaki et al., "Follow-up studies of children treated with a long-term intravenous nutrition (IVN) during the neonatal period," Journal of Pediatric Surgery, vol. 17, no. 1, pp. 37-42, 1982.

[21] J. Alverdy, H. S. Chi, and G. F. Sheldon, "The effect of parenteral nutrition on gastrointestinal immunity. The importance of enteral stimulation," Annals of Surgery, vol. 202, no. 6, pp. 681684, 1985.

[22] A. F. Hofmann, "Defective biliary secretion during total parenteral nutrition: probable mechanisms and possible solutions," Journal of Pediatric Gastroenterology and Nutrition, vol. 20, no. 4, pp. 376-390, 1995.

[23] E. Zambrano, M. El-Hennawy, R. A. Ehrenkranz, D. Zelterman, and M. Reyes-Múgica, "Total parenteral nutrition induced liver pathology: an autopsy series of 24 newborn cases," Pediatric and Developmental Pathology, vol. 7, no. 5, pp. 425-432, 2004.

[24] M. L. Forchielli and W. A. Walker, "Nutritional factors contributing to the development of cholestasis during total parenteral nutrition," Advances in Pediatrics, vol. 50, pp. 245-267, 2003.

[25] R. Utili, C. O. Abernathy, and H. J. Zimmerman, "Endotoxin effects on the liver," Life Sciences, vol. 20, no. 4, pp. 553-568, 1977. 
[26] J. C. Rooney, D. J. Hill, and D. M. Danks, "Jaundice associated with bacterial infection in the newborn," American Journal of Diseases of Children, vol. 122, no. 1, pp. 39-41, 1971.

[27] R. A. Vileisis, R. J. Inwood, and C. E. Hunt, "Prospective controlled study of parenteral nutrition-associated cholestatic jaundice: effect of protein intake," Journal of Pediatrics, vol. 96, no. 5, pp. 893-897, 1980.

[28] R. Rager and M. J. Finegold, "Cholestasis in immature newborn infants: is parenteral alimentation responsible?" Journal of Pediatrics, vol. 86, no. 2, pp. 264-269, 1975.

[29] S. Li, M. S. Nussbaum, D. Teague, C. L. Gapen, R. Dayal, and J. E. Fischer, "Increasing dextrose concentrations in total parenteral nutrition (TPN) causes alterations in hepatic morphology and plasma levels of insulin and glucagon in rats," Journal of Surgical Research, vol. 44, no. 6, pp. 639-648, 1988.

[30] B. Messing, J. F. Colombel, D. Heresbach, O. Chazouillères, and A. Galian, "Chronic cholestasis and macronutrient excess in patients treated with prolonged parenteral nutrition," Nutrition, vol. 8, no. 1, pp. 30-36, 1992.

[31] W. H. Wagner, A. C. Lowry, and H. Silberman, "Similar liver function abnormalities occur in patients receiving glucosebased and lipid-based parenteral nutrition," American Journal of Gastroenterology, vol. 78, no. 4, pp. 199-202, 1983.

[32] V. Colomb, A. Jobert-Giraud, F. Lacaille, O. Goulet, J.-C. Fournet, and C. Ricour, "Role of lipid emulsions in cholestasis associated with long-term parenteral nutrition in children," Journal of Parenteral and Enteral Nutrition, vol. 24, no. 6, pp. 345-350, 2000.

[33] M. Cavicchi, P. Beau, P. Crenn, C. Degott, and B. Messing, "Prevalence of liver disease and contributing factors in patients receiving home parenteral nutrition for permanent intestinal failure," Annals of Internal Medicine, vol. 132, no. 7, pp. 525-532, 2000.

[34] D. B. Allardyce, "Cholestasis caused by lipid emulsions," Surgery Gynecology and Obstetrics, vol. 154, no. 5, pp. 641-647, 1982.

[35] Y. Koga, V. L. Swanson, and D. M. Hays, "Hepatic "intravenous fat pigment" in infants and children receiving lipid emulsion," Journal of Pediatric Surgery, vol. 10, no. 5, pp. 641-648, 1975.

[36] J. H. Passwell, R. David, D. Katznelson, and B. E. Cohen, "Pigment deposition in the reticuloendothelial system after fat emulsion infusion," Archives of Disease in Childhood, vol. 51, no. 5, pp. 366-368, 1976.

[37] D. H. Adamkin, P. G. Radmacher, and R. L. Klingbeil, "Use of intravenous lipid and hyperbilirubinemia in the first week," Journal of Pediatric Gastroenterology and Nutrition, vol. 14, no. 2, pp. 135-139, 1992.

[38] D. D. Black, E. A. Suttle, and P. F. Whitington, “The effect of short-term total parenteral nutrition on hepatic function in the human neonate: a prospective randomized study demonstrating alteration of hepatic canalicular function," Journal of Pediatrics, vol. 99, no. 3, pp. 445-449, 1981.

[39] S. S. Toce and W. J. Keenan, "Lipid intolerance in newborns is associated with hepatic dysfunction but not infection," Archives of Pediatrics and Adolescent Medicine, vol. 149, no. 11, pp. 12491253, 1995.

[40] K. M. Gura, S. Lee, C. Valim et al., "Safety and efficacy of a fishoil based fat emulsion in the treatment of parenteral nutrition associated liver disease," Pediatrics, vol. 121, no. 3, pp. e678e686, 2008.

[41] I. P. J. Alwayn, C. Andersson, B. Zauscher, K. Gura, V. Nosé, and M. Puder, "Omega-3 fatty acids improve hepatic steatosis in a murine model: potential implications for the marginal steatotic liver donor," Transplantation, vol. 79, no. 5, pp. 606-608, 2005.

[42] J. E. Van Aerde, D. R. Duerksen, L. Gramlich et al., "Intravenous fish oil emulsion attenuates total parenteral nutrition-induced cholestasis in newborn piglets," Pediatric Research, vol. 45, no. 2, pp. 202-208, 1999.

[43] P. J. Javid, A. K. Greene, J. Garza et al., “The route of lipid administration affects parenteral nutrition-induced hepatic steatosis in a mouse model," Journal of Pediatric Surgery, vol. 40, no. 9, pp. 1446-1453, 2005.

[44] A. Wretlind, "Development of fat emulsions," Journal of Parenteral and Enteral Nutrition, vol. 5, no. 3, pp. 230-235, 1981.

[45] J. M. Bengoa, S. B. Hanauer, and M. D. Sitrin, "Pattern and prognosis of liver function test abnormalities during parenteral nutrition in inflammatory bowel disease," Hepatology, vol. 5, no. 1, pp. 79-84, 1985.

[46] B. Edgren and A. Wretlind, "The theoretical background of the intravenous nutrition with fat emulsions," Nutritio et Dieta, vol. 5, pp. 364-386, 1963.

[47] M. E. Ginn-Pease, D. Pantalos, and D. R. King, "TPN-associated hyperbilirubinemia: a common problem in newborn surgical patients," Journal of Pediatric Surgery, vol. 20, no. 4, pp. 436439, 1985.

[48] P. J. Javid, F. R. Malone, A. A. S. Dick et al., "A contemporary analysis of parenteral nutrition-associated liver disease in surgical infants," Journal of Pediatric Surgery, vol. 46, no. 10, pp. 1913-1917, 2011. 


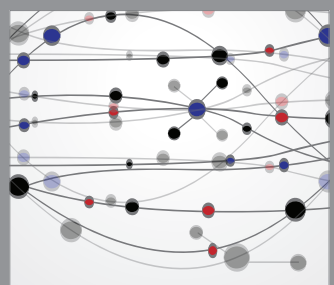

The Scientific World Journal
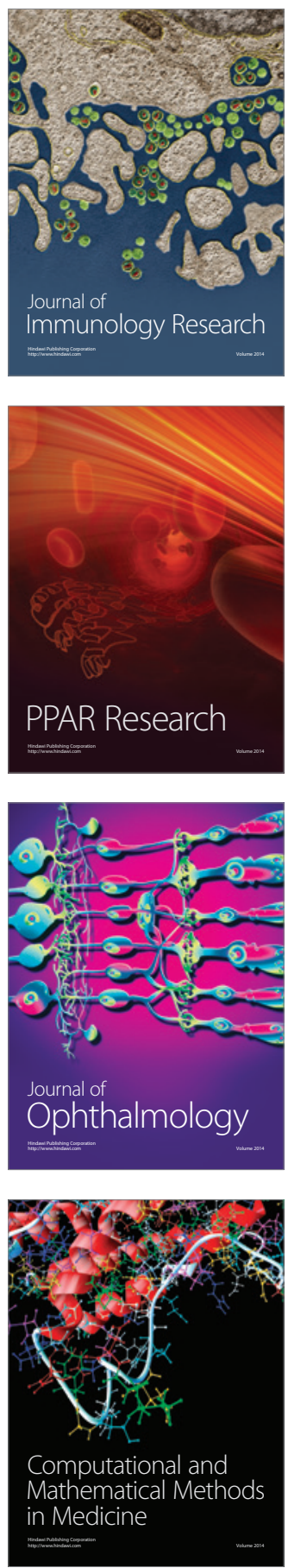

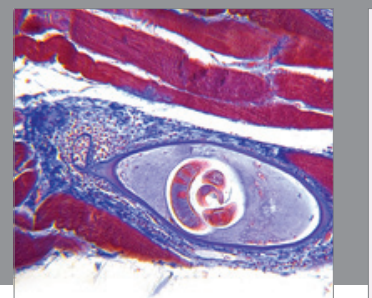

Gastroenterology

Research and Practice
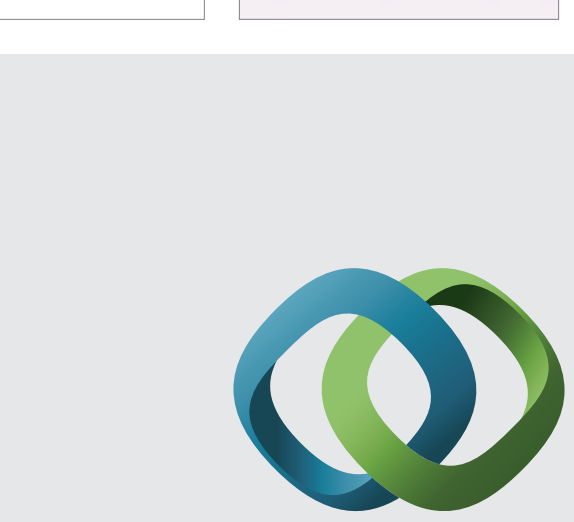

\section{Hindawi}

Submit your manuscripts at

http://www.hindawi.com
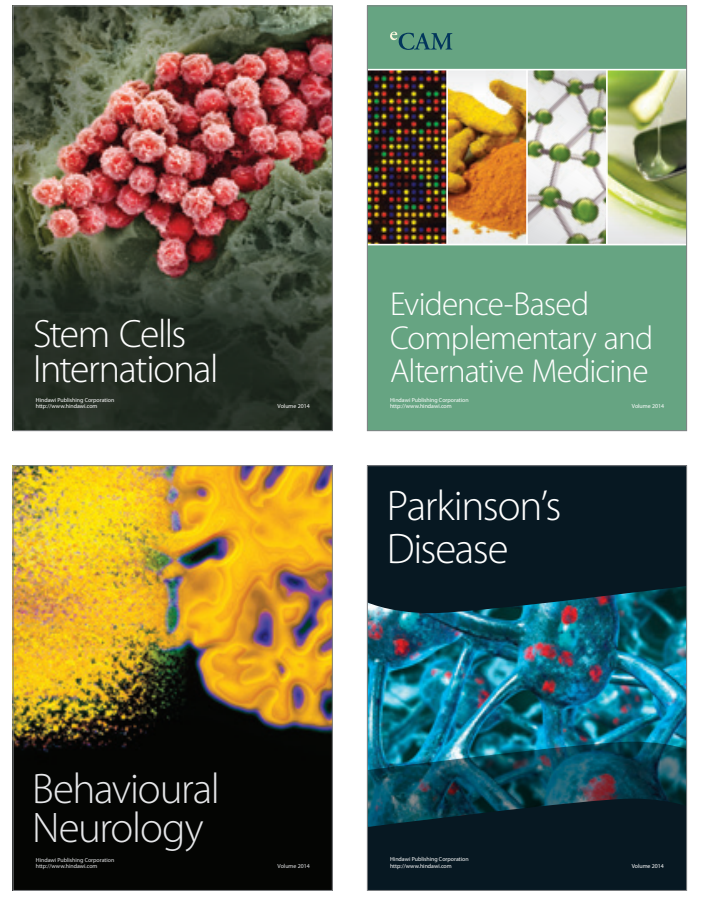
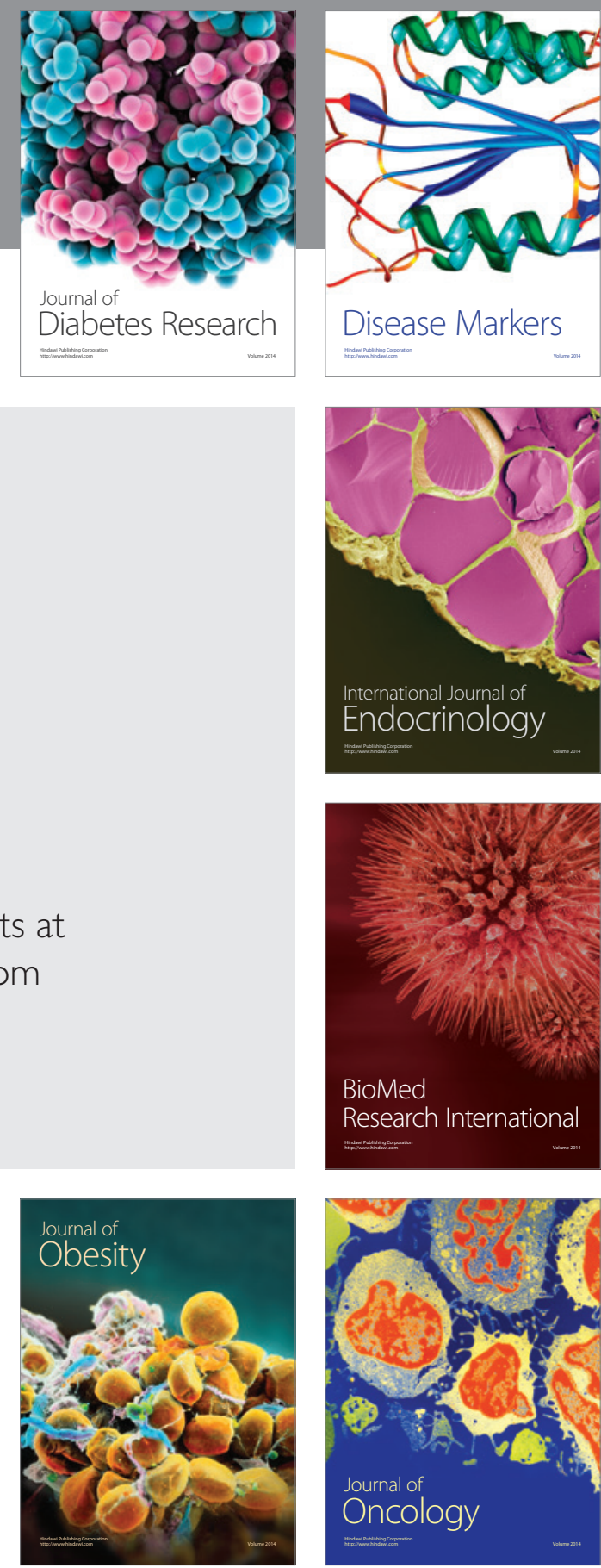

Disease Markers
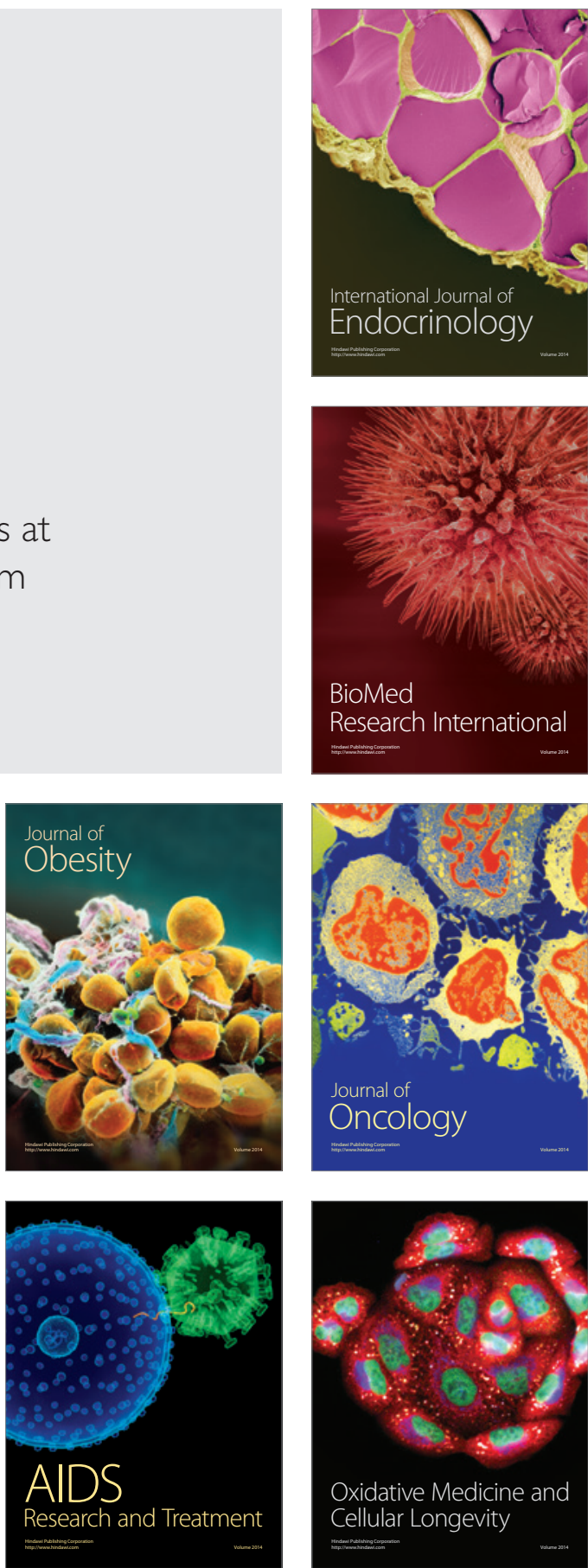